\title{
The Survey of Self-Regulation Behaviors and Related Factors in Elderly with Hypertension in South-East of Iran
}

\author{
Masoumeh Fuladvandi ${ }^{1}$, Hamid Safarpour ${ }^{2}$, Leila Malekyan ${ }^{1 *}$, Somayeh Moayedi ${ }^{1}$, \\ Maryam Askaryzadeh Mahani², Ebrahim Salimi ${ }^{3}$
}

\author{
${ }^{1}$ Department of Nursing, School of Nursing and Midwifery, Bam University of Medical Sciences, Bam, Iran \\ ${ }^{2}$ Department of Nursing, School of Nursing and Midwifery, Ilam University of Medical Sciences, Ilam, Iran \\ ${ }^{3}$ Department of Nursing, School of Nursing and Midwifery, Jundishapur University of Medical Sciences, \\ Ahvaz, Iran \\ Email: *1.malkyan@gmail.com
}

How to cite this paper: Fuladvandi, M., Safarpour, H., Malekyan, L., Moayedi1, S., Mahani, M.A. and Salimi, E. (2017) The Survey of Self-Regulation Behaviors and Related Factors in Elderly with Hypertension in South-East of Iran. Health, 9, 592-600.

https://doi.org/10.4236/health.2017.94042

Received: November 21, 2016

Accepted: April 8, 2017

Published: April 11, 2017

Copyright (c) 2017 by authors and Scientific Research Publishing Inc. This work is licensed under the Creative Commons Attribution International License (CC BY 4.0).

http://creativecommons.org/licenses/by/4.0/

\begin{abstract}
Hypertension is one of the most important risk factors for heart diseases today. The effect of hypertension in the elderly is higher than other age groups and it may lead to changes in their quality of life. By the increase of age, the amount of self-care behaviors of patients with hypertension decreased. Therefore, control and self-care behaviors are so important. This study has been conducted to study self-regulation behaviors and Associated Factors in elderly patients with hypertension. This study was a cross sectional, descriptive analytic study, which was conducted using multistage sampling on the elderly 60 years and above with hypertension. The sample size was calculated 365 and the final sample size of 380 people was considered by possible losses. The instruments include of demographic and self-regulatory behaviors questionnaire. The results showed that self-regulation of behavior was $42.3 \%$ of the total score. In terms of quality, only $7.4 \%$ of the elderly had good behavior, $46.6 \%$ of poor performance, and the rest were mediocre performance. Age ( $\mathrm{p}$ $=0.03)$, gender $(p=0.02)$, education $(p=0.001)$, income level $(p=0.03)$ and marital status $(\mathrm{p}=0.001)$ significantly associated with behaviors of self-regulation. The results generally indicate unfavorable self-regulation of elderly patients with hypertension. Some variables such as gender, age, marital status, education and income levels were associated with these behaviors. So paying attention to the education of the elderly in care centers is essential.
\end{abstract}

\section{Keywords}

Self-Regulation, Elderly, Hypertension, Bam 


\section{Introduction}

Today, considering medical, economic and social advances, mortality rate is decreased and life expectancy increases. In fact, over time, the world population is ageing rapidly, so that WHO has called this century as ageing century [1]. According to the latest report of World Health Organization in 2016, the overall average life expectancy was 71.4 years. According to the results of World Health Organization's survey based on information obtained in 2016, life expectancy index was 74.5 and 76.6 years for Iranian men and women, respectively [2]. Although developed countries and countries with thriving economies have the highest number of elderly people,

Elderly population will be significantly increased in developing countries, particularly in Asia so that it is estimated that $72 \%$ of world's elderly people, i.e. about 860 million people will be reliving in developing countries in 2050 [1].

Today, population growth rate in Iran is $1.3 \%$, while the growth rate of population aged over 60 years is $4.3 \%$ [3]. According to the United Nations Population Fund (UNFPA), now people over 60 years make up $8.1 \%$ of the total population of Iran. However, the elderly population growth rate is much higher than that of other population groups. Accordingly, the annual world population growth rate is less than $1.5 \%$, while for the elderly aged between 60 to 65 years the same rate is about $4.3 \%$ [3]. It is anticipated that the number of Iranian elderly reach to approximately 12 million by 2030 [4]. Due to changes in life styles as result of the increase in chronic diseases, especially in the older ages, more than $50 \%$ of deaths are attributable to cardiovascular diseases and strokes [5]. Hypertension is one of the most important risk factors for atherosclerosis, heart failure, stroke and kidney failure in many countries [6]. Hypertension is a second risk factor, to which the greatest burden of disease is attributed. In 2015, the disease burden attributable to hypertension was estimated 3.7\% (or 57 million DALY) [7]. Hypertension has become a health problem all societies due to its high prevalence rate and serious complications [8]. Long-term calorie intake more than the amount of energy consumed, long-term consumption of excessive sodium diet, obesity, alcohol consumption, sedentary life and psychosocial stresses are involved in development of hypertension [9] [10]. On the hand, the prevalence of hypertension is associated with increasing age so that its prevalence rate in the elderly over 60 years has been reported $60 \%$ to $70 \%$ [11]. Increased hypertension in the elderly leads to increased disability and mortality rate among them. Also, the hypertension's side effects are more severe in the elderly than other age groups and may cause changes in their quality of life [12]. According to the World Health Organization's report in 2014, about 14,104 people died from the hypertension; i.e. about $4.19 \%$ of the total deaths or $26.38 \%$ per hundred thousand people [13]. It is very important to control hypertension following its development [14]. The results of previous studies show that selfregulation interventions and self-care behaviors have been very effective in reducing the blood pressure as well as reducing its related deaths. With increasing age, self-care behaviors in patients with hypertension are reduced [15]. There- 
fore, following the development of hypertension, hypertension control and self-care behaviors in elderly people are of paramount importance. Self-regulation is an important personal characteristic which strongly affects one's actions and behavior and described as the ability to develop, implement, and maintain planned behavior in order to achieve personal goals [16]. Self-regulation can be seen as the voluntary control of emotional, attentional, and behavioural impulses in the service of personally valued goals and standards [17]. Generally, self-regulation is the basic ability of the individual to regulate oneself in relation to the environment and personal goals. In doing this, the individual overcomes the discrepancy between one's expectations and the reality [16] [18].

Studies have shown that hypertension control rate is low so that the control hypertension in the adult population in America was 40.3\% [19]. Barati [12] and Delavari [14] also showed that the quality of self-regulation behaviors is low in rural populations in Iran. Considering that there are few studies on self-regulation behaviors of hypertension among the elderly and related factors, the present study aimed to investigate the frequency of these behaviors and related factors in the city of Bam, Iran.

\section{Methods}

This study was a cross sectional, descriptive analytic study, which was conducted using multistage sampling on the elderly 60 years and above with hypertension in city of Bam, the South-East of Iran in 2016. According to the formula, based on data from previous studies, $\mathrm{P}=0.6, \mathrm{~d}=0.5, \mathrm{Z}=1.96$, the sample size was calculated 365 and the final sample size of 380 people was considered by possible losses. Inclusion criteria included elderly 60 years and above with having personal health records and a history of at least one year of hypertension. Exclusion criteria was individuals' unwillingness to participate in the study and also who that has not enough Consciousness. Multistage sampling method was used and a total of 33 locations in the city of Bam were selected in the first phase considering the sample size. Then, one elderly patient with hypertension was randomly selected in every neighborhood by referring to the homes of people and $12 \mathrm{el}-$ derly patients from households close to the first patient were randomly selected and entered into the study. Upon referring to the houses without elderly people in them or patients lacking the inclusion criteria, the next door house would be used.

The interviewers included three nurses who were trained equally in a briefing for questioning, data registration and measuring variables, especially blood pressure. The interviewers used the interview method while filling out the questionnaires. It should be noted that to confirm the hypertension in these elderly people, the elderly were first asked about their disease, taking pills for high blood pressure and if their response was positive, an analog sphygmomanometer (Richter Brand) was used to measure their blood pressure. The JNC VII criterion was used in order to measure their blood pressure [20]. According to this criterion, hypertension refers to $140 \mathrm{~mm} \mathrm{Hg}$ systolic hypertension and above or di- 
astolic blood pressure $90 \mathrm{~mm} \mathrm{Hg}$ or above or use of antihypertensive drugs in the past month. These patients were asked about their anti-hypertensive and their responses were recorded. While measuring the elderly's blood pressure by the analog sphygmomanometer, their blood pressure was taken from their dominant hand in a sitting position after ten minutes break so that their arm was placed on a hard support at the heart level.

In the next step, demographic information (age, gender, education level, marital status, family history of hypertension, occupation and income levels) of patients with hypertension were measured. Then to measure self-regulation behaviors of patients, a researcher-made questionnaire was used. This questionnaire contains questions, which allow patients to report their self-regulation behaviors in the past week.

The questionnaire components include lack of smoking, regular blood pressure checks, physical activity at an acceptable level (3 sessions per week for at least 20 minutes), avoid fatty foods, avoid solid cooking oils, regular use of medication, relaxation exercise and regular monitoring of weight. Options of these questions were identified using statements, including "yes always" (2 points), "Yes, sometimes" (1 point) and "No" (0 point).

Thus, the self-regulatory minimum and maximum scores ranged from 0 to 16.After scoring, the total score was calculated as the sum of all self-regulation questions and were classified in three categories: poor (less than $50 \%$ of the total score), medium (between 50 and $75 \%$ of the total score) and desirable (more than $75 \%$ of the total score). The content validity of the questionnaire was approved by 10 professionals, including 3 health education and health promotion specialist and 7 nursing specialists.

In order to confirm the reliability of the study, a pilot study was conducted on 20 elderly patients with hypertension within two stages at an interval of one week. The intra-class correlation coefficient of (ICC $=71 \%$ ) as well as Cronbach's alpha coefficient of $78 \%$ were achieved. After data collection, data analysis was performed using SPSS-18 software. First, normality of data distribution was confirmed using Kolmogorov-Smirnov test. Then, parametric independent $\mathrm{t}$ test was used to compare the averages in two groups. Also, one-way ANOVA was used to compare mean scores of self-regulation in more than two independent groups. The test level of significance was considered as $\mathrm{P} \leq 0.05$.

\section{Results}

This study was conducted on 380 patients with hypertension, 25 of whom were excluded because of incomplete information. The findings showed there were 225 men (59.2\%) men and 155 women (40.8\%) in the present study.

The age range and the mean age of patients were 60 to 86 and 67.3 years, respectively.

Overall, the average score of self-regulation behaviors in all patients was 6.76 \pm 2.87 . Considering that the maximum possible score is 16 , it can be said that the mean score of self-regulation of the patients was $42.3 \%$ of the total score. Also, 
$46.1 \%, 46.6 \%$ and $7.4 \%$ of patients had poor regulation performance, average performance and a good performance in terms of quality (Table 1). Among the self-regulatory behaviors, use of liquid oils and lack of smoking respectively had the best and a more unfavorable situation compared with others behaviors.

According to independent T-test, men's self-care score was significantly higher than that of women $(\mathrm{P}=0.02)$. Also, there was a significant difference between average score of self-regulation behaviors obtained by two age groups so that the status of self-regulation behaviors in the $60-75$ age group than patients over 75 years $(\mathrm{P}=0.03)$. Married, widow and divorced patients respectively accounted for $70 \%, 24.2 \%$ and $5.8 \%$ of the patients.

There were a total of $37.6 \%$ illiterate patients, $28.2 \%$ primary school, $28.4 \%$ middle and high school and 5.8\% high school graduates and above. According to analysis of variance, the frequency of self-regulation behaviors in marital $(\mathrm{P}=$ $0.001)$ and educational groups $(\mathrm{P}=0.001)$ was significantly different.

In addition, $39 \%$ of patients reported that they have observed the disease in their close relatives. There was no significant relationship between family history and self-regulation behaviors. Also, there was no significant correlation between job and self-regulation behaviors variables. Finally, analysis of variance showed that there was a relationship between income level and the level of self-regulation behaviors $(\mathrm{P}=0.003)$.

\section{Discussion}

This study which aimed to evaluate self-regulation behaviors in elderly patients with hypertension in the city of Bam, showed that self-regulation behaviors accounted for $42.3 \%$ of the total score. In terms of quality, only $7.4 \%$ of the elderly have had desired behaviors and $46.6 \%$ of them had poor performance, and the rest had moderate performance. In a study to evaluate self-regulation behaviors in hypertensive patients in rural population, Delavari et al. (14] concluded that the level of these behaviors is undesirable, which is consistent with the present study. Barati et al. also reported that the frequency of self-regulation behaviors in adults with hypertension was at the moderate level. In a study conducted by Barati, like the present study, only $7.9 \%$ of adults had a desired performance and also $73.8 \%$ of them had moderate performance [12]; but in this study, only $46.1 \%$ of patients had moderate performance, which is probably due to the much younger average age of the population participated in Barati's study compared with the present study.

Many other studies have reported that the level of self-regulation behaviors

Table 1. Distribution of the studied units by the scores of self-regulation behaviors.

\begin{tabular}{cc}
\hline The Performance of Self-Regulation & Number (\%) \\
\hline Weak & $175(46.1 \%)$ \\
Average & $177(46.6 \%)$ \\
Good & $28(7.4 \%)$ \\
\hline
\end{tabular}


was undesirable in patients with hypertension [15] [21]. So obviously, planning for empowerment and promotion of self-regulation behaviors in elderly patients with hypertension and even other chronic diseases is essential. The present study showed that among self-regulation behaviors, consumption of cooking oils had the highest frequency, which is probably due to the government measures to produce and promote these products in recent years as well as raise awareness about the harms of solid oils. On the other hand, the least frequent behavior was lack of smoking; that is it had a more unfavorable situation than other self-regulation behaviors, which is consistent with the study conducted by Barati [12] and Khosravi [21]. The undesirable status of smoking is due the fact that quitting such behavior requires high self-efficacy and thus more attention should paid to the promotion of the elderly's self-efficacy in controlling or quitting smoking.

In the present study, men significantly outperformed women, which is consistent with the study conducted by Baghianimoghadam [15].According to the social structure and roles of men and the more obstacles facing women self-regulation behaviors are more frequent in men. Also, men were more self-efficient and independent and therefore had better self-regulation behaviors [22].On the other hand, women due to housekeeping as well as more obstacles have fewer opportunities for adopting such behaviors [14]. The present study indicates the reduced self-regulation behaviors with increasing age. Rockwell's study [23] also reported the similar result. It seems that aging and the subsequent increased hearing, visual, cognitive and physical disorders lead to the elderly's dependency and reduced self-efficacy among the elderly towards adopting self-regulation behaviors. In the present study, there was a significant relationship between level of education and self-regulation behaviors, which is consistent with several other studies [15] [24] [25]. With increasing literacy, the elderly's level of awareness and responsibility is increased. Some studies reported that awareness level is an important predictor of key health behaviors [26]. Rakwell suggests that patients with higher level of education have better decision-making powers to adopt health behaviors [20]. Some studies state that some people with low level of education do not understand the instructions correctly and this leads to a lack of self-efficacy in the adoption of these behaviors [27]. In the analysis of other factors, there was a significant relationship between marital status and self-regulation behaviors so that the average self-regulation performance of married individuals was better compared to other groups. Married people enjoy more support from the other people, especially their family.

The families are one of the most valuable supports, emotional and information sources, which encourage them (married individuals) to adopt healthy behaviors [21]. Finally, there was a significant relationship between income level and self-regulation behaviors. The economic factor is one of the most important factors related to levels of health. Families with high income level have more power to adopt some behaviors such as buying cooking oils, buying sphygmomanometer, use of sport equipment at home and many other behaviors. 


\section{Conclusions}

The results of the present study generally indicated the undesirable status of the self-regulation behavior among the elderly patients with hypertension. Some variables such as gender, age, marital status, education level and income level were significantly related with these behaviors. So obviously, planning for empowerment and promotion of self-regulation behaviors in elderly patients with hypertension and even other chronic diseases is essential.

Also, it is essential to pay attention to the education of the elderly in health care centers.

Of course, these trainings should be provided properly so that the elderly with low level of education and physical problems also benefit from it.

\section{Recommendations for Future Studies}

One of the main limitations of this study was that the study population was selected from urban areas. It is recommended to conduct further studies on rural populations. Another limitation of this study was that the elderly's perceived obstacles in adopting self-regulatory behaviors were not investigated. It is recommend to consider solutions to improve the elderly's self-efficacy, especially the elderly with health, hearing and cognitive problems in future research. Also, it seems necessary to consider the elderly's perceived obstacles in adopting selfregulation behaviors. In addition, considering that self-regulation behaviors were less frequent in the elderly whose spouses had passed away and divorced than the married elderly, it is recommended to pay more attention to these groups in other studies.

\section{Acknowledgements}

The authors express their gratitude to experts, nurses, the elderly patients, and their families who helped us in conducting this study.

\section{References}

[1] Zhao, Y., Yan, H., Marshall, R.J., Dang, S., Yang, R., Li, Q. and Qin, X. (2013) Trends in Population Blood Pressure and Prevalence, Awareness, Treatment, and Control of Hypertension among Middle-Aged and Older Adults in a Rural Area of Northwest China from 1982 to 2010. PLoS ONE, 8, e61779. https://doi.org/10.1371/journal.pone.0061779

[2] World Population Prospects, The 2015 Revision (WPP2015). United Nations DESA, Population Division, New York.

[3] United Nations Fund for Population Activities (UNFPA) (2015) State of the World's Population 2015: Unleashing the Potential of Urban Growth. UNFPA, New York. http://www.unfpa.org/

[4] World Health Organization (2016) World Health Statistics 2016: Monitoring Health for the SDGs, Sustainable Development Goals.

[5] Mozaffarian, D., Benjamin, E.J., Go, A.S., et al. (2015) Heart Disease and Stroke Statistics-2015 Update: A Report from the American Heart Association. Circulation, 131, e29-e322. https://doi.org/10.1161/CIR.0000000000000152 
[6] World Health Organization (WHO) (2013) A Global Brief on Hypertension: Silent Killer, Global Public Health Crisis. http://www.thehealthwell.info/node/466541

[7] World Health Organization (2015) Global Health Observatory (GHO) Data. http://www.who.int/gho/tb/en

[8] Hering, D., Coca, A., Cunha, P., Gasecki, D., Lovic, D., Sierra, C. and Zaninnelli, A. (2016) Update on Hypertension Management. Hypertension, 17.

[9] Fagard, R.H. (2002) Epidemiology of Hypertension in the Elderly. The American Journal of Geriatric Cardiology, 11, 23-28. https://doi.org/10.1111/j.1076-7460.2002.00856.x

[10] Prince, M.J., Wu, F., Guo, Y., Robledo, L.M., O’Donnell, M., Sullivan, R. and Yusuf, S. (2015) The Burden of Disease in Older People and Implications for Health Policy and Practice. The Lancet, 385, 549-562. https://doi.org/10.1016/S0140-6736(14)61347-7

[11] Glynn, R.J., Field, T.S., Hebert, P.R., Taylor, J.O., Hennekens, C.H. and Rosner, B. (1995) Evidence for a positive Linear Relation between Blood Pressure and Mortality in Elderly People. The Lancet, 345, 825-829.

https://doi.org/10.1016/S0140-6736(95)92964-9

[12] Barati, M., Darabi, D., Moghimbeigi, A. and Afsar, A. (2011) [Investigate the Factors Associated with Self-Regulatory Behaviors on Blood Pressure in Patients with Hypertension City Bahar in the 2010]. Journal of Fasa University of Medical Sciences, 1, 60-65.

[13] World Health Organization (WHO). Global Health Observatory (GHO) Data. http://www.who.int/gho/en/

[14] Delavari, A., Hori, N., Haghighi, S., Amini, M., Aali, K.S., Gouya, M.M., et al. (2007) Prevalence of Hypertension in Iranian Urban and Rural Populations Aged over 20 Years in 2004. Journal of Mazandaran University of Medical Sciences, 17, 79-86.

[15] Baghianimoghadam, M., Aivazi, S., Mzloomy, S.S. and Baghianimoghadam, B. (2011) Factors in Relation with Self-Regulation of Hypertension, Based on the Model of Goal Directed behavior in Yazd City. Journal of Medicine and Life, 4, 30-35.

[16] Brown, J.M., Miller, W.R. and Lawendowski, L.A. (1999) The Self-Regulation Questionnaire. In: Vandecreek, L. and Jackson, T.L., Eds., Innovations in Clinical Practice: A Sourcebook, Vol. 17, Professional Resource Press/Professional Resource Exchange, Sarasota, FL, 281-292.

[17] Duckworth, A.L. and Carlson, S.M. (2015) Self-Regulation and School Success. In: Sokol, B.W., Grouzet, F.M.E. and Müller, U., Eds., Self-Regulation and Autonomy: Social and Developmental Dimensions of Human Conduct, Cambridge University Press, New York, 208-230.

[18] Carver, C.S. and Scheier, M.F. (2011) Self-Regulation of Action and Affect. In: Vohs, K. and Baumeister, R.F., Eds., Handbook of Self-Regulation: Research, Theory, and Applications, The Guilford Press, New York, 3-21.

[19] Guo, F., He, D., Zhang, W. and Walton, R.G. (2012) Trends in Prevalence, Awareness, Management, and Control of Hypertension among United States Adults, 1999 to 2010. Journal of the American College of Cardiology, 60, 599-606. https://doi.org/10.1016/j.jacc.2012.04.026

[20] Chobanian, A.V., Bakris, G.L., Black, H.R., Cushman, W.C., Green, L.A., Izzo Jr., J.L. and Roccella, E.J.; National Heart, Lung, and Blood Institute Joint National Committee on Prevention, Detection, Evaluation, and Treatment of High Blood Pressure; National High Blood Pressure Education Program Coordinating Com- 
mittee (2003) The Seventh Report of the Joint National Committee on Prevention, Detection, Evaluation, and Treatment of High Blood Pressure: The JNC 7 Report. $J A M A, 289,2560-2572$.

[21] Khosravi, A., Pourheidar, B., Roohafza, H., Moezzi, M., Mousavi, M., Hajiannejad, A., et al. (2014) Evaluating Factors Associated with Uncontrolled Hypertension: Isfahan Cohort Study, Iran. ARYA Atherosclerosis, 10, 311-318.

[22] Carlson, B., Riegel, B. and Moser, D.K. (2001) Self-Care Abilities of Patients with Heart Failure. Heart \& Lung. The Journal of Acute and Critical Care, 30, 351-359. https://doi.org/10.1067/mhl.2001.118611

[23] Rockwell, J.M. and Riegel, B. (2001) Predictors of Self-Care in Persons with Heart Failure. Heart \& Lung: The Journal of Acute and Critical Care, 30, 18-25. https://doi.org/10.1067/mhl.2001.112503

[24] Chin, Y.F., Huang, T.T. and Hsu, B.R.S. (2013) Impact of Action Cues, Self-Efficacy and Perceived Barriers on Daily Foot Exam Practice in Type 2 Diabetes Mellitus Patients with Peripheral Neuropathy. Journal of Clinical Nursing, 22, 61-68. https://doi.org/10.1111/j.1365-2702.2012.04291.x

[25] Dela Cruz, F.A. and Galang, C.B. (2008) The Illness Beliefs, Perceptions, and Practices of Filipino Americans with Hypertension. Journal of the American Academy of Nurse Practitioners, 20, 118-127. https://doi.org/10.1111/j.1745-7599.2007.00301.x

[26] Holm, C.J., Frank, D.I. and Curtin, J. (1999) Health Beliefs, Health Locus of Control, and Women's Mammography Behavior. Cancer Nursing, 22, 149-156. https://doi.org/10.1097/00002820-199904000-00007

[27] Warren-Findlow, J., Seymour, R.B. and Huber, L.R.B. (2012) The Association between Self-Efficacy and Hypertension Self-Care Activities among African American Adults. Journal of Community Health, 37, 15-24. https://doi.org/10.1007/s10900-011-9410-6

\section{Submit or recommend next manuscript to SCIRP and we will provide best} service for you:

Accepting pre-submission inquiries through Email, Facebook, LinkedIn, Twitter, etc. A wide selection of journals (inclusive of 9 subjects, more than 200 journals)

Providing 24-hour high-quality service

User-friendly online submission system

Fair and swift peer-review system

Efficient typesetting and proofreading procedure

Display of the result of downloads and visits, as well as the number of cited articles

Maximum dissemination of your research work

Submit your manuscript at: http://papersubmission.scirp.org/

Or contact health@scirp.org 